\title{
Enhancement of goblet cell hyperplasia and airway hyperresponsiveness by salbutamol in a rat model of atopic asthma
}

\author{
A Kamachi, M Munakata, Y Nasuhara, M Nishimura, Y Ohtsuka, M Amishima, \\ T Takahashi, Y Homma, Y Kawakami
}

\begin{abstract}
Background-Goblet cell hyperplasia (GCH) is a prominent feature in animal models of atopic asthma produced by immunisation and following multiple challenges with antigens. The aim of this study was to examine the effect of a $\beta_{2}$ agonist on the development of GCH induced by the immune response.

Methods-Brown Norway rats were immunised and challenged with an aerosol of ovalbumin for four weeks. Salbutamol ( $0.5 \mathrm{mg} / \mathrm{kg} / \mathrm{day})$ or vehicle was continuously delivered for the four weeks using a subcutaneously implanted osmotic minipump. The density of goblet cells, other morphological changes, and airway responsiveness to methacholine were evaluated 24 hours after the final challenge.

Results-Treatment with salbutamol induced a more than twofold increase in the mean (SE) number of goblet cells (53.7 (7.3) vs 114.5 (11.8) cells $/ 10^{3}$ epithelial cells, $p<0.01$ ) while it did not significantly influence airway wall thickening and eosinophilic infiltration. Airway responsiveness to methacholine expressed as the logarithmic value of the concentration of methacholine required to generate a $50 \%$ increase in airway pressure $\left(\operatorname{logPC} \mathrm{C}_{150} \mathrm{Mch}\right)$ was also enhanced by the $\beta_{2}$ agonist $(-0.56$ $(0.21)$ vs $-0.95(0.05), p<0.05)$. Additional experiments revealed that the same dose of the $\beta_{2}$ agonist alone did not cause GCH in non-immunised rats and that the enhancement of GCH by salbutamol was completely abolished by simultaneous treatment with methylprednisolone (0.5 mg/kg/day).

Conclusions-These data suggest that salbutamol enhances goblet cell hyperplasia and airway hyperresponsiveness in this rat model of atopic asthma.

(Thorax 2001;56:19-24)
\end{abstract}

Keywords: bronchial asthma; salbutamol; goblet cell hyperplasia

Goblet cell hyperplasia (GCH), an increase in the number of goblet cells in the airway epithelium, is a characteristic pathological change observed in bronchial asthma and chronic bronchitis. ${ }^{12}$ The resulting hypersecretion of mucus associated with $\mathrm{GCH}$ causes airway narrowing and thus contributes to airflow obstruction. In fatal cases of status asthmaticus it has been repeatedly reported that marked $\mathrm{GCH}$ is a prominent feature in the airways. ${ }^{3-5}$

Immunisation and multiple challenges with some antigens induce marked $\mathrm{GCH}$ in animal models of atopic asthma. ${ }^{6-8}$ There is accumulating evidence that $\mathrm{GCH}$ is part of the phenotypic expression of atopic asthma ${ }^{910}$ because allergen induced inflammation responsible for atopic asthma is also considered to be involved in $\mathrm{GCH}$. Indeed, interleukin (IL)-4 induces mucin gene expression and goblet cell metaplasia in vivo as well in vitro. ${ }^{11} \mathrm{IL}-13$, another potential contributor to allergic asthma, leads to $\mathrm{GCH}$ in vivo. ${ }^{912}$ However, previous studies have shown that non-allergic stimuli such as cigarette smoke and sulphur dioxide can induce GCH in rat models. ${ }^{13}{ }^{14}$ Furthermore, two early reports showed that $\beta$ agonists such as isoprenaline can cause $\mathrm{GCH}$ and secretory gland hypertrophy in rats. ${ }^{15}{ }^{16}$ Beta agonists are also known to cause enlargement of salivary glands in rats which is characterised by mitotic proliferation of the serous, mucous, and duct cells and associated with increased secretory activity. ${ }^{17}$

The aim of this study was to examine the effect of the $\beta_{2}$ agonist salbutamol on the development of GCH in a murine model of atopic asthma. We were specifically interested in the possible interactions between the $\beta_{2}$ agonist and airway inflammatory responses in the development of GCH. Other morphological changes of the airways, including eosinophilic infiltration and the increase in wall thickness, were evaluated as well as airway responsiveness to methacholine.

\section{Methods}

ANIMALS AND IMMUNISATION

Specific pathogen-free six week old male Brown Norway rats (weight range 160-210 g) were purchased from Japan Charles River Co. The rats were kept in a conventional colony in a Hokkaido University animal care facility and allowed to feed and drink freely. They were actively immunised to ovalbumin (OA). They were first injected subcutaneously with $1 \mathrm{mg}$ OA dissolved in gel containing $200 \mathrm{mg}$ aluminum hydroxide. An adjuvant $(1 \mathrm{ml})$ consisting of $10^{9}$ heat killed Bordetella pertussis organisms was intraperitoneally injected at the same time. Two weeks after immunisation the rats inhaled $5 \% \mathrm{w} / \mathrm{v}$ OA for five minutes in an exposure chamber $(35 \times 25 \times 20 \mathrm{~cm})$ which allowed six animals to be put in at the same time. Identical challenges with inhaled OA were then repeated 
Experiment 1

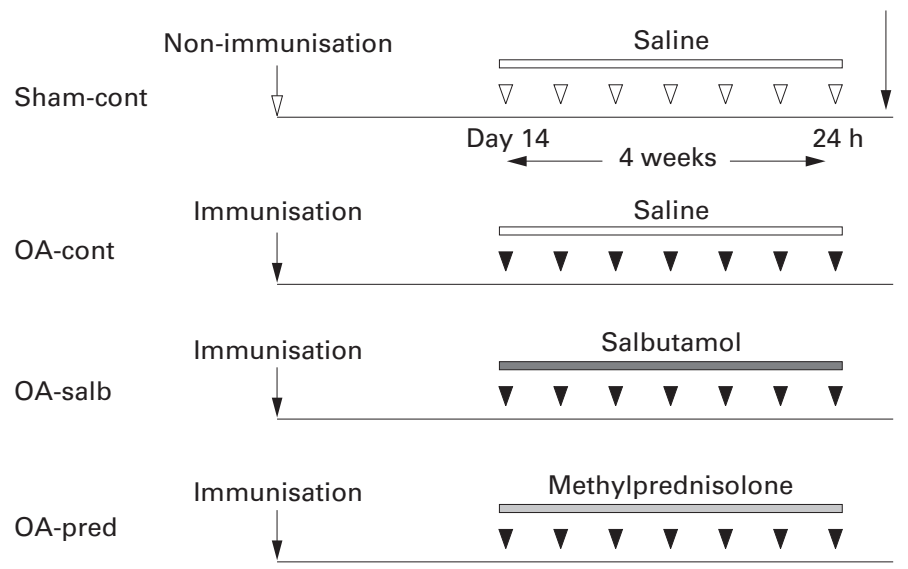

Experiment 2

\begin{tabular}{|c|c|c|c|c|c|c|c|c|}
\hline \multicolumn{2}{|c|}{ Non-immunisation } & \multicolumn{7}{|c|}{ Saline } \\
\hline \multirow{2}{*}{ Sham-cont } & $\nabla$ & $\nabla$ & $\nabla$ & $\nabla$ & $\nabla$ & $\nabla$ & $\nabla$ & $\nabla$ \\
\hline & & ay & & 4 & reek & & & $24 \mathrm{~h}$ \\
\hline \multicolumn{2}{|c|}{ Non-immunisation } & \multicolumn{7}{|c|}{ Salbutamol } \\
\hline Sham-salb & & $\nabla$ & $\nabla$ & $\nabla$ & $\nabla$ & $\nabla$ & $\nabla$ & $\nabla$ \\
\hline
\end{tabular}

OA-salb Immunisation \begin{tabular}{c} 
Salbutamol \\
\cline { 2 - 3 }
\end{tabular}

Figure 1 Time line figures of the first and second experiments. White arrowheads represent immunisation or inhalational challenges with saline; black arrowheads represent immunisation or inhalational challenges with ovalbumin.

for the same rats every four days for the following four weeks. For inhalation challenge, OA was dissolved in saline and then aerosolised with an ultrasonic nebuliser (NE-U11B, Omuron Co, Tokyo, Japan) which delivered the aerosol at $1 \mathrm{ml} / \mathrm{min}$.

EXPERIMENTAL PROTOCOL

Sham control (sham-cont) rats were initially injected with sterile saline instead of OA and then received repeated saline inhalation in the same manner. After four weeks of repeated inhalation challenge with OA or saline the airway responsiveness to methacholine was measured and histological analysis of the airways was performed on all animals. The experimental protocol is shown in fig 1 .

In the first experiment the OA immunised rats were divided into three groups according to treatment during the period of inhalation challenge. Salbutamol (Sigma Chemical Co, St Louis, Missouri, USA), methylprednisolone (Sigma Chemical Co), or sterile saline was given during the four weeks using a subcutaneously implanted osmotic minipump (Alzet model 2ML4; Alza Co, Palo Alto, CA, USA) that allowed continuous delivery of the drug. These groups were called OA-cont, OA-salb, and OA-pred according to treatment.

For implantation of the pump four hours after the first inhalation challenge the rats were anaesthetised with an intraperitoneal injection of urethane $(0.25 \mathrm{~g} / \mathrm{ml})$. A small incision was made at the surface between the scapulae to form a pocket in the subcutaneous connective tissue. The pump was inserted into the pocket and the incision was closed with sutures.

Salbutamol or methylprednisolone were dissolved in sterile saline with a concentration that maintained the administration rate at $0.5 \mathrm{mg} /$ $\mathrm{kg}$ /day. To confirm whether a sufficient amount of salbutamol was delivered by the osmotic pump throughout the experiment the plasma concentration of salbutamol was measured by high pressure liquid chromatography on days 7 and 21 in two rats that received the drug in the same manner but without the aerosol challenge. ${ }^{18}$

Salbutamol markedly enhanced the development of GCH in the OA immunised rats in the first experiment so we then examined whether salbutamol alone could cause GCH in the non-immunised rats and also whether methylprednisolone could inhibit the enhancing effect of the $\beta_{2}$ agonist on $\mathrm{GCH}$ induced by the immune response. For this purpose the rats were divided into four groups: sham-cont, sham-salb, OA-salb, and OA-salb+pred. The former two groups did not receive immunisation and were treated either with sterile saline or salbutamol for the following four weeks as described in the first experiment. The other two groups received immunisation with $\mathrm{OA}$ and then were treated with salbutamol alone $(0.5 \mathrm{mg} / \mathrm{kg} /$ day $)$ or salbutamol and methylprednisolone (each at $0.5 \mathrm{mg} / \mathrm{kg} /$ day) delivered from the same osmotic minipump. In this second experiment aerosol was inhaled for 10 minutes at each challenge, twice as long as in the first experiment, to ensure sufficient exposure of the airway.

These experimental protocols and procedures were approved by the ethical committee on animal research, Hokkaido University School of Medicine.

MEASUREMENT OF AIRWAY RESPONSIVENESS TO METHACHOLINE

For the measurement of airway responsiveness to methacholine the rats were anaesthetised by intraperitoneal injection of pentobarbital sodium $(50 \mathrm{mg} / \mathrm{kg}) 24$ hours after the final challenge. A metallic tube of $2 \mathrm{~mm}$ internal diameter was inserted into the trachea. The rats were then mechanically ventilated with an animal ventilator (Rodent Ventilator Model 683, Harvard Apparatus Inc, Holliston, Massachusetts, USA) with a tidal volume of $6 \mathrm{ml} / \mathrm{kg}$ and frequency of 100 breaths/min. Airway opening pressure (Pao) was continuously measured through the side port of the tracheostomy tube by a pressure transducer (TP603T, Nihon Kohden Co, Tokyo, Japan) and recorded on a polygraph for later analysis. After measurement of baseline Pao while the animals were inhaling physiological saline for one 


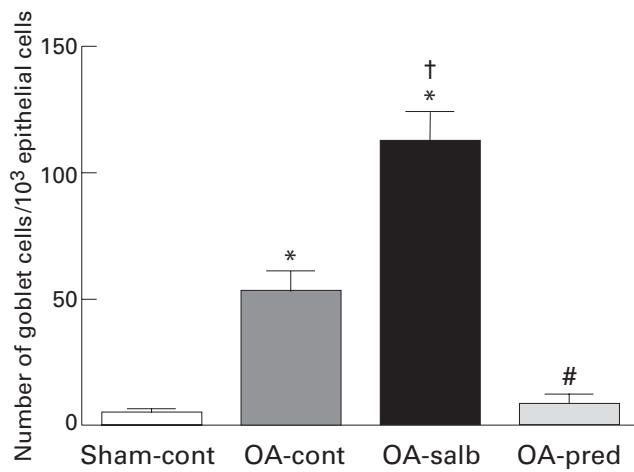

Figure 2 Degree of goblet cell hyperplasia according to treatment, expressed as the number of goblet cells/1000 epithelial cells of the large airways. sham-cont $=$ sham control $(n=5)$, OA-cont = ovalbumin control $(n=5)$, $O A-$ salb = ovalbumin + salbutamol $(n=5)$, OA-pred $=$ ovalbumin + methylprednisolone $(n=4)$. All values are mean (SE). ${ }^{\star} p<0.01$ compared with sham-cont. $t_{p}<0.01$ compared with $O A$-cont. \#p<0.01 compared with $O A$-cont and $O A$-salb.

minute, methacholine was given in progressively doubling doses from $0.0625 \mathrm{mg} / \mathrm{ml}$ for one minute at each dose until the Pao reached a plateau. The airway responsiveness to methacholine was assessed by the concentration of methacholine required to generate a 50\% increase in $\mathrm{Pao}$ from the baseline level $\left(\mathrm{PC}_{150} \mathrm{Mch}\right)$.

\section{MEASUREMENT OF GCH AND EOSINOPHILIC}

INFILTRATION IN AIRWAYS

The rats were exsanguinated from the aorta immediately after the measurement of airway responsiveness to methacholine. The left lung was fixed with an intrabronchial infusion of $10 \%$ neutral formalin at a constant pressure of $25 \mathrm{~cm} \mathrm{H}_{2} \mathrm{O}$ for a period of 48 hours and then $5 \mu \mathrm{m}$ thick paraffin embedded midsagittal sections were prepared. They were stained with Alcian blue and periodic acid-Schiff (AB/PAS) as well as haematoxylin and eosin $(\mathrm{H} / \mathrm{E})$ to evaluate the density of goblet cells and
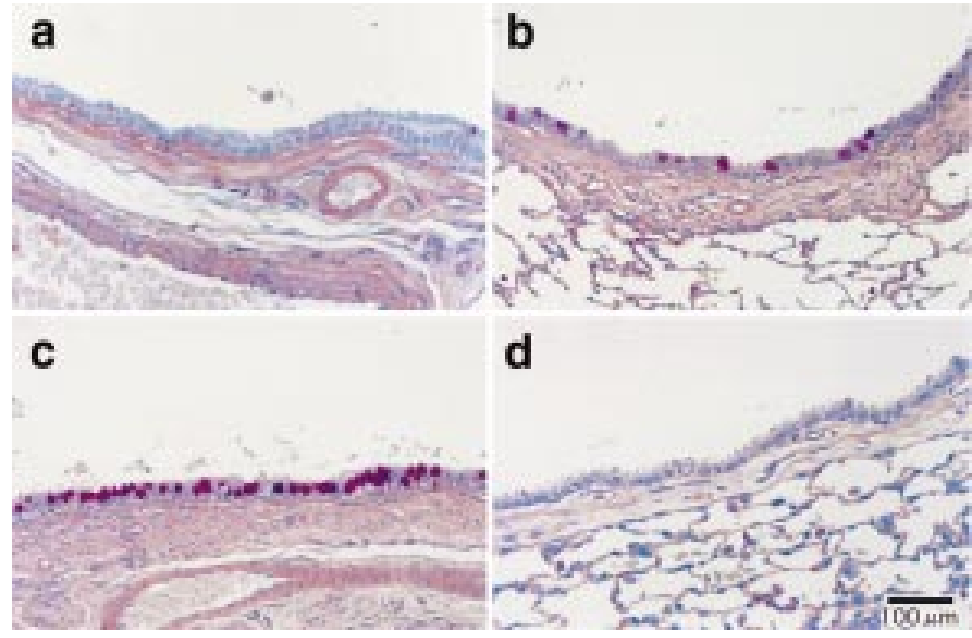

Figure 3 Representative demonstration of goblet cell hyperplasia according to treatment. Goblet cells of large airways are stained with AB-PAS (original magnification $\times 200$ ). (A) Sham-cont group: only a small number of goblet cells are identified in a control rat. (B) $O A$-cont group: marked goblet cell hyperplasia is observed in an ovalbumin-immunised rat. (C) OA-salb group: treatment with salbutamol further enhances goblet cell hyperplasia in an ovalbumin immunised rat. (D) OA-pred group: treatment with methylprednisolone completely abolishes goblet cell hyperplasia in an ovalbumin immunised rat. For definitions of groups see legend to fig 2 . eosinophils in the airways. We defined the large airways as those with a basement membrane length of $\geqslant 2.0 \mathrm{~mm}$ when cut transversely. Goblet cells were mostly found in the large airways before and after multiple antigen challenges, regardless of treatment with salbutamol. They were examined microscopically at a magnification of $\times 400$ by an independent observer who was blind to any other data.

Epithelial cells containing abundant mucus stained pink or purple in their cytoplasm were identified as goblet cells. Total epithelial cells, including goblet cells, were counted for more than five large airways per section. We evaluated at least 200 consecutive epithelial cells lining the same airway not adjacent to lymphoid tissue. The density of goblet cells was expressed as the number of goblet cells $/ 1000$ epithelial cells, and this index was used for comparison between the groups.

The number of eosinophils in the submucosal area of the large airways was counted in $\mathrm{H} / \mathrm{E}$ stained sections (five large airways per section, not adjacent to lymphoid tissue). Eosinophils were clearly identified by their eosin positive granules in the cytoplasm. Degranulated cells were not counted. The total number of eosinophils was divided by the length of the basement membrane measured using a computerised image analyser (XL10, Olympus Co, Tokyo, Japan) for comparisons between the groups.

MORPHOMETRIC ANALYSIS OF AIRWAYS

The epithelial thickness (area internal to the basement membrane) and wall thickness (area outside the basement membrane) of the large airways were measured in paraffin embedded sections stained with $\mathrm{H} / \mathrm{E}$. The areas of smooth muscle were also measured on sections stained with an antibody to $\alpha$-smooth muscle actin (Smooth Muscle Actin 1A4, Daco Japan Co, Tokyo, Japan) which enabled us to differentiate muscles from surrounding connective tissues. Only airways that were transversely cut and had a ratio of long/short diameter of $<2$ were analysed with the image analyser. All areas were divided by the squared length of the basement membrane to standardise the airway size.

ANALYSIS OF DATA

Statistical analysis of $\mathrm{PC}_{150}$ methacholine was performed on log transformed data. Comparisons of data between groups were performed using one way analysis of variance (ANOVA). As a post hoc test, means within the groups were compared by Fisher's protected least significant difference procedure. Data are expressed as mean (SE); p values of $<0.05$ were considered significant.

\section{Results}

NUMBERS OF GOBLET CELLS AND EOSINOPHILS IN THE AIRWAYS

The number of goblet cells markedly increased with multiple antigen challenges in the OAcont group compared with the sham-cont group (fig 2). Treatment with salbutamol induced an increase of more than twofold in the number of goblet cells compared with the 


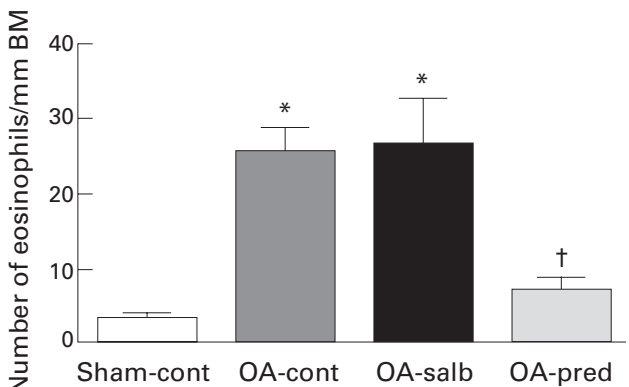

Figure 4 Infiltration of eosinophils in the large airways according to treatment, expressed as the total number of eosinophils divided by the length of the basement membrane $(B M)$ : sham-cont $(n=5), O A$-cont $(n=5), O A-s a l b$ $(n=5), O A$-pred $(n=4)$. All values are mean (SE). ${ }^{\star} p<0.01$ compared with sham-cont; $t p<0.01$ compared with $O A$-cont and $O A$-salb. For definitions of groups see legend to fig 2 .

Table 1 Morphological analysis of the large airways

\begin{tabular}{llll}
\hline & $A S M\left(\times 10^{-3}\right)$ & $A W\left(\times 10^{-3}\right)$ & Epi $\left(\times 10^{-3}\right)$ \\
\hline Sham-cont (n=5) & $3.6(0.2)$ & $10.4(1.0)$ & $5.0(0.4)$ \\
OA-cont (n=6) & $3.3(0.2)$ & $14.2(1.2) \dagger$ & $7.2(0.5) \dagger$ \\
OA-salb (n=5) & $2.9(0.4)$ & $13.1(1.1)$ & $7.4(0.7) \dagger$ \\
OA-pred (n=4) & $3.3(0.4)$ & $12.0(0.7)$ & $6.3(0.6)$
\end{tabular}

Sham-cont $=$ sham control; OA-cont $=$ ovalbumin control; OA-salb = ovalbumin + salbutamol; OA-pred $=$ ovalbumin + methylprednisolone; ASM = airway smooth muscle; $\mathrm{AW}=$ airway wall; Epi = epithelium.

All areas were divided by the squared length of the basement membrane $\left(\right.$ area $\left./ \mathrm{mm}^{2}\right)$. Data are expressed as mean (SE). $\mathrm{tp}<0.05$ compared with sham-cont.

OA-cont group, while treatment with methylprednisolone completely inhibited $\mathrm{GCH}$ in antigen challenged rats. Typical pathological changes observed in these cases are shown in fig 3. The number of eosinophils in the airway walls also significantly increased in the OAcont group compared with the sham-cont group (fig 4). In contrast with $\mathrm{GCH}$, however, the airway infiltration of eosinophils was not enhanced at all by treatment with salbutamol, although it was again completely inhibited by treatment with methylprednisolone (fig 4).

MORPHOLOGICAL CHANGES OF AIRWAY WALLS The epithelial layer and the airway wall area significantly increased in the OA-cont group compared with the sham-cont group but the area of airway smooth muscle was unchanged (table 1). However, there were no differences either in the area of airway wall or in the epithelial layer between OA-cont and OA-salb rats (table 1). In rats treated with methylprednisolone none of the three indices changed significantly in comparison with the mean values of sham-cont rats (table 1).

AIRWAY RESPONSES TO METHACHOLINE

As shown in fig 5, the airway responsiveness to methacholine was significantly increased in the OA-cont group compared with the sham-cont group and further enhanced in the OA-salb group compared with the OA-cont group. However, this airway hyperresponsiveness to methacholine was again completely inhibited by treatment with methylprednisolone.

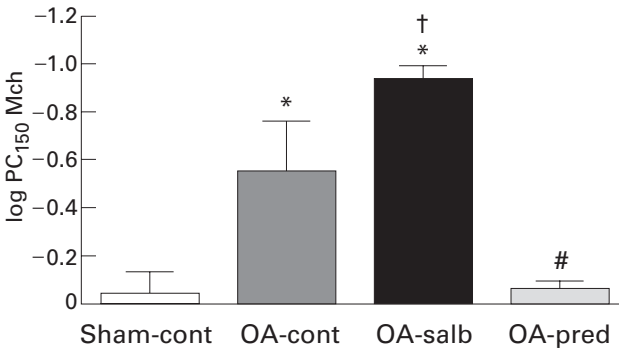

Figure 5 Airway responsiveness to methacholine expressed as $\log P C$ methacholine according to treatment: sham-cont $(n=5), O A$-cont $(n=5), O A$-salb $(n=5), O A$-pred $(n=4)$. All values are mean $(S E) .{ }^{\star} p<0.01$ compared with sham-cont and $p<0.05$ compared with $O A$-cont; $t p<0.05$ compared with $O A$-cont; $\# p<0.05$ compared with $O A$-cont and $O A$-salb.

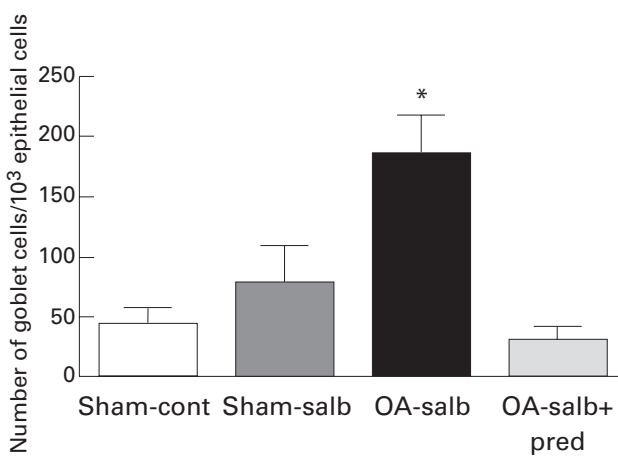

Figure 6 Effect of salbutamol alone on $G C H$ and methylprednisolone on the GCH observed in an $O A$-salb model: sham-cont $(n=6)$, sham-salb $(n=6), O A$-salb $(n=3), O A$-salb + pred $(n=3)$. All values are mean $(S E)$ ${ }^{\star} p<0.05$ compared with the other three groups.

EFFECTS OF SALBUTAMOL ALONE ON GCH AND OF METHYLPREDNISOLONE ON GCH OBSERVED IN THE OA-SALB MODEL

The same dose of salbutamol as was used in the first experiment $(0.5 \mathrm{mg} / \mathrm{kg} /$ day $)$ did not significantly enhance GCH in the nonimmunised rats in the second experiment (fig 6 ). The number of goblet cells in sham-cont and OA-salb groups was larger than that observed in the first experiment. This may be explained by the difference in the exposure time to the aerosol between the two experiments ( $5 \mathrm{~min}$ vs $10 \mathrm{~min}$ ) and by the difference in the body weights of the rats when killed (sham-cont 224 (7) g vs 288 (9) g; OA-salb 246 (7) g vs 280 (10) g, p<0.05 for both). Methylprednisolone completely abolished the enhancing effect of the $\beta_{2}$ agonist on $\mathrm{GCH}$ induced by the immune response observed in the first experiment.

PLASMA CONCENTRATION OF SALBUTAMOL

The plasma concentration of salbutamol was $4.1 \mathrm{ng} / \mathrm{ml}$ on day 7 and $5.4 \mathrm{ng} / \mathrm{ml}$ on day 21 after the implantation of the osmotic minipump. These values are comparable to the therapeutic range for human subjects treated with $4 \mathrm{mg}$ oral salbutamol every eight hours. ${ }^{19}$

\section{Discussion}

In this study we have shown that OA sensitised rats had a more than twofold increase in the number of goblet cells after repeated challenges with OA for four weeks when treated with salb- 
utamol during that period compared with rats similarly challenged with OA without salbutamol. However, airway wall thickening and eosinophilic infiltration, which are also characteristic features in this rat model of atopic asthma, were not significantly influenced by salbutamol treatment. These data indicate that the $\beta_{2}$ agonist specifically enhanced GCH induced by the immune response. In addition, we found that salbutamol treatment also caused enhancement of airway hyperresponsiveness to methacholine in these rats and that simultaneous treatment with methylprednisolone could completely inhibit both the GCH and the airway hyperresponsiveness observed in the salbutamol treated rats. These data provide further evidence that glucocorticoids are powerful inhibitors of the enhancing effect of a $\beta_{2}$ agonist on $\mathrm{GCH}$ as well as airway hyperresponsiveness in this rat model of atopic asthma.

It has been reported that GCH occurs in the airways of animal models as well as in humans in response to a number of stimuli. Exogenous inhaled irritants such as cigarette smoke, ${ }^{13}$ sulphur dioxide, ${ }^{14}$ and nitrogen dioxide ${ }^{20}$ are known to increase the size of bronchial submucosal glands and the number of goblet cells. Sturgess and Reid were the first to show that GCH could be produced in a rat model by systemically administered drugs. ${ }^{15}$ They reported that both isoprenaline (a non selective $\beta_{2}$ adrenergic agonist) and pilocarpine (a cholinergic agonist) increased the number of goblet cells and mucus secretion in the trachea and bronchial trees when given intravenously six times. The same group of investigators later reported that the selective $\beta_{2}$ agonist salbutamol also caused GCH in rat airways, although it was not so prominent as that induced by isoprenaline.$^{21}$ It should be mentioned that, prior to these reports, there had been accumulating evidence supporting the role of non-selective $\beta_{2}$ adrenergic agonists in the development of hypertrophy and hyperplasia of acinar cells in parotid and submaxillary glands of rats and mice. ${ }^{1722}$

In our study salbutamol alone did not cause $\mathrm{GCH}$ in the non-immunised rats. The discrepancy between our results and those of the previously mentioned reports might be explained by several factors. Firstly, the dose of salbutamol we used was in the range of the therapeutic dose for human diseases whereas in earlier studies doses more than 100 times higher were used. ${ }^{21}$ Indeed, the previous studies showed that the severity of GCH caused by isoprenaline or salbutamol was dependent on the dose and the injection frequency of these drugs. ${ }^{21}$ Secondly, salbutamol, a selective $\beta_{2}$ adrenergic agonist, may not be as potent as a non-selective $\beta$ agonist in inducing $\mathrm{GCH}$ when not given in combination with other inducers of $\mathrm{GCH}$, as was the case in a previous study. ${ }^{21}$ Thirdly, the method of administration was different. We used an osmotic minipump for drug delivery which probably kept the plasma level of salbutamol stable throughout the experiment, while previous studies used repeated intravenous injections which are likely to have resulted in fluctuations in blood levels of the injected drug.

Of particular importance in this study was the fact that salbutamol, given in a clinically relevant dose, did not cause GCH in the nonimmunised rats and markedly enhanced GCH in the airways of the OA sensitised rats. It is beyond the scope of this study to investigate the mechanisms by which $\mathrm{GCH}$ is enhanced by the $\beta_{2}$ agonist in multiple antigen challenged rats. However, there are several possible explanations.

Firstly, the $\beta_{2}$ agonist may have direct or indirect enhancing effects on the immune mechanism responsible for the development of $\mathrm{GCH}$. Several lines of evidence indicate that the development of GCH is mediated by Th2 cytokines such as IL-4 and IL-13. ${ }^{911}{ }^{12}$ IL-4 induces mucin gene expression and $\mathrm{GCH}$ in vivo as well as in vitro. ${ }^{11}$ It has also been suggested that some immune mechanisms contribute to the development of $\mathrm{GCH}$ in a number of animal models of atopic asthma..$^{6-8}$ Furthermore, a recent report indicated that tumour necrosis factor (TNF) $-\alpha$ and epidermal growth factor (EGF) play a part in the development of $\mathrm{GCH}$ in a rat model with atopic asthma. ${ }^{8}$ If $\beta_{2}$ agonists have any positive interaction with these cytokines at any level of the immune mechanism, it is conceivable that $\beta_{2}$ agonists and the immune mechanism might together contribute to the development of GCH. On the other hand, eosinophils are unlikely to be involved in the development of GCH. A previous study showed that an antibody to IL-5 did not inhibit GCH despite significant reduction of eosinophilic infiltration in the airways in a murine model of atopic asthma. ${ }^{23}$ In this study we found that salbutamol enhanced $\mathrm{GCH}$ without any effects on eosinophilic infiltration in the airways, thus supporting the concept that eosinophils are not key players in the development of $\mathrm{GCH}$.

The second theoretical explanation for the enhancing effect of the $\beta_{2}$ agonist on $\mathrm{GCH}$ in this experiment is that the $\beta_{2}$ agonist may allow inhalation of larger amounts of antigens into the lungs because of its bronchodilating action, thus resulting in the enhancement of airway inflammation. ${ }^{24} \mathrm{We}$, however, consider this unlikely for two reasons: (1) there was no evidence of enhancement of airway inflammation by the $\beta_{2}$ agonist because there was no change in eosinophilic infiltration in the airways as stated above; and (2) there was no visible enhancement of $\mathrm{GCH}$ in the smaller airways with the $\beta_{2}$ agonist (data not shown).

Thirdly, we must consider the possibility that the long term administration of a $\beta_{2}$ agonist may work to inhibit the anti-inflammatory effect of endogenous catecholamines via downregulation or tachyphylaxis of $\beta_{2}$ adrenoceptors. ${ }^{25-27}$ Contrary to the first explanation proposed above, $\beta_{2}$ agonists are believed to have anti-inflammatory effects under certain circumstances. For instance, they are reported to inhibit the release of chemical mediators such as histamine, leukotrienes, and cytokines including $\mathrm{TNF}-\alpha$ in IgE mediated mast cell activation. ${ }^{28}{ }^{29}$ Some recent studies also sug- 
gested that $\beta_{2}$ agonists could inhibit the release of IL- 4 and IL-13 from antigen stimulated basophils by increasing the level of cyclic AMP. ${ }^{30}$ Reduction of the anti-inflammatory effects of the $\beta_{2}$ agonist by downregulation or tachyphylaxis of its receptors after the administration of salbutamol may result in the exacerbation of airway inflammation followed by marked enhancement of GCH.

Finally, it must be noted that a non- $\beta_{2}$ action of salbutamol might also be involved in the enhancement of GCH. We did not examine whether the effect of salbutamol on $\mathrm{GCH}$ was directly mediated by $\beta_{2}$ adrenergic receptors.

In this study salbutamol caused significant enhancement of airway hyperresponsiveness to methacholine in addition to the development of $\mathrm{GCH}$. This observation is consistent with some previous studies using animal models of atopic asthma. ${ }^{31-33}$ Both airway hyperresponsiveness and $\mathrm{GCH}$ are characteristic of bronchial asthma. It remains to be determined whether any common mechanisms exist between the two. One possibility is that GCH contributes to the enhancement of bronchial responsiveness to methacholine by changing epithelial barrier function. For instance, Yanta et $a l^{34}$ showed that the number of secretory cells in the airways was positively correlated with airway hyperresponsiveness in dogs with naturally developing airway hyperresponsiveness. Alternatively, enhancement of airway inflammation by salbutamol, but not of eosinophilic infiltration, might have similarly influenced airway hyperresponsiveness and $\mathrm{GCH}$ in this study.

In conclusion, we have shown in this study that salbutamol, in a clinically relevant dose, has the potential to enhance $\mathrm{GCH}$ and airway hyperresponsiveness to methacholine in a rat model of atopic asthma when systemically and continuously administered using an osmotic pump. Since such enhancement of GCH did not occur with the same dose of salbutamol when given to non-immunised rats, we conclude that the $\beta_{2}$ agonist enhances $\mathrm{GCH}$ induced by the immune response and that this can be completely abolished by simultaneous treatment with glucocorticoids. Although it may be premature to suppose that this phenomenon is applicable to humans, one should keep in mind the possibility that regular use of $\beta_{2}$ agonists may exacerbate $\mathrm{GCH}$ and the resulting mucus hypersecretion in patients with bronchial asthma. Further study of the mechanisms of this phenomenon might provide insights into the roles of $\beta_{2}$ agonists and glucocorticoids in the treatment of bronchial asthma in humans.

1 Glynn AA, Michaels L. Bronchial biopsy in chronic bronchitis and asthma. Thorax 1960;15:142-53.

2 Dunnill MS. The pathology of asthma with special reference to changes in the bronchial mucosa. F Clin Pathol 1960;13: 27-33.

3 Messer JW, Peters GA, Bennett WA. Cause of death and pathologic findings in 304 cases of bronchial asthma. Dis Chest 1960;38:616-24.

4 Houston JC, De Navasquez S, Trounce JR. A clinical and pathological study of fatal cases of status asthmatics. Thorax 1953;8:207-13.

5 Aikawa T, Shimura S, Sasaki H, et al. Marked goblet cell hyperplasia with mucus accumulation in the airways of hyperplasia with mucus accumulation in the airways of
patients who died of severe acute asthma attack. Chest 1992;101:916-21. $6 \begin{aligned} & \text { Blyth DI, Pedrick MS, Savage TJ, et al. Induction, duration, } \\ & \text { and resolution of airway goblet cell hyperplasia in a murine }\end{aligned}$ and resolution of airway goblet cell hyperplasia in a murine model of atopic asthma: effect of concurrent infection with
respiratory syncytial virus and response to dexamethasone. respiratory syncytial virus and response to

7 Blyth DI, Pedrick MS, Savage TJ, et al. Lung inflammation and epithelial changes in a murine model of atopic asthma. Am f Respir Cell Mol Biol 1996;14:425-38.

8 Takeyama K, Dabbagh K, Lee HM, et al. Epidermal growth factor system regulates mucin production in airways. Proc Natl Acad Sci USA 1999;96:3081-6.

9 Wills-Karp M, Luyimbazi J, Xu X, et al. Interleukin-13: central mediator of allergic asthma. Science 1998;282: 2258-61.

10 Ahlstedt S, Enander I. Immune regulation of goblet cell development. Int Arch Allergy Appl Immunol 1987;82:35760.

11 Dabbagh K, Takeyama K, Lee HM, et al. IL-4 induces mucin gene expression and goblet cell metaplasia in vitro mucin gene expression and goblet cell met

12 Grünig G, Warnock M, Wakil AE, et al. Requirement for L-13 independently of IL-4 in experimental asthma. Science 1998;282:2261-3.

13 Jones R, Bolduc P, Reid L. Goblet cell glycoprotein and tracheal gland hypertrophy in rat airways: the effect of tobacco smoke with or without the anti-inflammatory agent
phenylmethyloxadiazole. $B r \mathcal{F}$ Exp Pathol 1973;54:229-39. phenylmethyloxadiazole. Br F Exp Pathol 1973;54:229-39. tochemical changes in mucus in rat bronchial epithelium during exposure to sulphur dioxide. 7 Pathol Bacteriol 1968;96:97-111.

15 Sturgess J, Reid L. The effect of isoprenaline and pilocarpine on (a) bronchial mucus-secreting tissue and (b) pancreas, salivary glands, heart, thymus, liver and spleen. Br f Exp Pathol 1973;54:388-403.

16 Baskerville A. The development and persistence of bronchial gland hypertrophy and goblet-cell hyperplasia in the pig after injection of isoprenaline. F Pathol 1976;119:35-47.

17 Selye H, Veilleux R, Cantin M. Excessive stimulation of salivary gland growth by isoproterenol. Science 1961;133:44-5.

18 Hutchings MJ, Paull JD, Morgan DJ. Determination of salbutamol in plasma by high-performance liquid chromatography with fluorescence detection. I Chromatogr 1983; 277:423-6.

19 Morgan DJ, Paull JD, Richmond BH, et al. Pharmacokinetics of intravenous and oral salbutamol and its sulphate conjugate. Br f Clin Pharmacol 1986;22:587-93.

20 Freeman G, Haydon GB. Emphysema after low level exposure to $\mathrm{NO}_{2}$. Archs Environ Health 1964;8:125-8.

21 Jones R, Reid L. $\beta$-Agonists and secretory cell number and intracellular glycoproteins in airway epithelium. The effect intracellular glycoproteins in airway epithelium. The effect 21 .

22 Brown-Grant K. Enlargement of salivary gland in mice reated with isopropyl noradrenaline. Nature 1961;191: $1076-8$

23 Mathur M, Herrmann K, Li X, et al. TRFK-5 reverses established airway eosinophilia but not established hyperresponsiveness in a murine model of chronic asthma. Am f Respir Crit Care Med 1999;159:580-7.

24 Lai CKW, Twentyman OP, Holgate ST. The effect of an increase in inhaled allergen dose after rimiterol hydrobromide on the occurrence and magnitude of the late asthmatic response and the associated change in nonspecific bronchial responsiveness. Am Rev Respir Dis 1989;140: 917-23.

25 Cockcroft DW, Swystun VA. Functional antagonism: tolerance produced by inhaled $\beta_{2}$ agonists. Thorax 1996;51: 1051-6.

26 Hayes MJ, Qing F, Rhodes CG, et al. In vivo quantification of human pulmonary $\beta$-adrenoceptors: effect of $\beta$-agonis therapy. Am F Respir Crit Care Med 1996;154:1277-83.

27 Nishikawa M, Mak JCW, Shirasaki H, et al. Long-term exposure to norepinephrine results in down-regulation and reduced mRNA expression of pulmonary $\beta$-adrenergic receptors in guinea pigs. Am F Respir Cell Mol Biol 1994;10: 91-9.

28 Church MK, Hiroi J. Inhibition of IgE-dependent histamine release from human dispersed lung mast cells by antiallergic drugs and albuterol. Br F Pharmacol 1987;90:4219.

29 Bissonnette EY, Befus AD. Anti-inflammatory effect of beta 2-agonists: inhibition of TNF-alpha release from human mast cells. F Allergy Clin Immunol 1997;100:825-31.

30 Shichijo M, Shimizu Y, Hiramatsu K, et al. Cyclic AMP-elevating agents inhibit mite-antigen-induced IL-4 aMP-elevating agents inhibit mite-antigen-induced IL-4 and IL-13 release from basophil-enriched leukocyte

31 Mazzoni L, Naef R, Chapman ID, et al. Hyperresponsiveness of airways following exposure of guinea-pigs to racemic mixtures and distomers of $\beta_{2}$-selective sympathomimetics. Pulmonol Pharmacol 1994;7:367-76.

32 Buchheit K, Hofmann A, Fozard JR. Salbutamol-induced airway hyperreactivity in guinea pigs is not due to a loss of its bronchodilator effect. Eur F Pharmacol 1995;287:85-8.

33 Wang ZL, Bramley AM, McNamara A, et al. Chronic fenoterol exposure increases in vivo and in vitro airway responses in guinea pigs. Am $\mathcal{F}$ Respir Crit Care Med 1994; 149:960-5.

34 Yanta MA, Snapper JR, Ingram Jr RH, et al. Airway responsiveness to inhaled mediators: relationship to epithelial thickness and secretory cell number. Am Rev Respir Dis 1981;124:337-40. 